\title{
A INFLUÊNCIA DO AMBIENTE ESCOLAR NA ESCOLHA METODOLÓGICA PARA EDUCAÇÃO AMBIENTAL EM UMA ESCOLA DO CAMPO
}

\author{
Roberta Maidana da Silva ${ }^{1}$ \\ Toshio Nishijima ${ }^{2}$ \\ Marjana Machado dos Santos3
}

Resumo: $O$ presente estudo teve como finalidade verificar a influência do ambiente na escolha da metodologia de Educação Ambiental por professores dos anos iniciais do ensino fundamental de uma escola do campo de Júlio de Castilhos, RS. Assim, teve como objetivo analisar o uso da área externa da escola, a prática pedagógica em turmas multisseriadas, e a influência do meio rural na formação dos alunos. Para isto foi realizado um questionário com professores dos anos iniciais do ensino fundamental de uma escola do campo na cidade de Júlio de Castilhos (RS). Conclui-se que o meio externo é utilizado raras vezes durante as aulas de Educação Ambiental e os alunos relacionam as aulas com o dia a dia deles. Portanto, o ambiente escolar influencia em parte a escolha das metodologias do professor, sendo que as classes multisseriadas limitam muito a diversificação de metodologias de Educação Ambiental.

Palavras-chave: Educação do Campo; Ensino Fundamental; Práticas Pedagógicas; Consciência Ambiental.

1Universidade Federal de Santa Maria. E-mail: robertamaidana@yahoo.com.br, Link para o Lattes: http://lattes.cnpq.br/2601376215454295

2Universidade Federal de Santa Maria. E-mail: toshionishijima@gmail.com. Link para o Lattes: http://lattes.cnpq.br/5427442140441172

3Universidade Federal de Santa Maria. E-mail: marjanamachado@gmail.com.

Link para o Lattes: http://lattes.cnpq.br/0068127921848130 
Abstract: The present study aimed to verify the influence of the environment in the choice of environmental education methodology by teacher from the initial years of elementary education at school in the field of Júlio de Castilhos, RS. Thus, it aimed to analyze the use of the external area of the school, the pedagogical practice in multi-series classes and the influence of the rural environment in the formation of the students. For this, a questionnaire was conducted with teachers from the early years of elementary school at a rural school in the city of Júlio de Castilhos (RS). It was concluded that the external environment is rarely used during environmental education classes and with that the students relate the lessons to their daily lives. Therefore, the school environment influences in part the choice of the teacher's methodologies, the multi-series classes limit the diversification of environmental education methodologies.

Keywords: Field Education; Elementary Education; Pedagogical Practice; Environmental Awareness

\section{Introdução}

O planeta Terra é composto de inúmeros ecossistemas que ao longo dos anos modificam-se pela ação de fenômenos naturais ou pelas atividades humanas. Estes ambientes abrigam inúmeras espécies de seres vivos, além dos recursos naturais dos quais estes dependem. Os seres humanos, que igualmente compartilham o meio com os outros organismos, também são dependentes de recursos oriundos da natureza para todas as atividades básicas, como moradia, alimentação ou trabalho, e a partir disso, modificam o ambiente natural, alterando assim, os ecossistemas originais. Logo, essas modificações geram impacto ambiental irreparável, causando destruição da natureza, poluição dos recursos naturais, extinção de espécies, e consequências que afetam não só o presente, mas também o futuro das próximas gerações.

Os impactos ambientais estão sendo percebidos pelo mundo inteiro, originados naturalmente ou causados por atividades humanas, sendo estas, consideradas mais graves e na maioria das vezes irreversíveis. Os diferentes impactos ambientais ocorrem principalmente em função do tipo de relação que o ser humano estabelece com o meio ambiente. Contudo, a Educação Ambiental está intimamente ligada ao indivíduo como ser social, portanto, é importante a percepção individual como elemento da prática ou disseminação de uma educação voltada ao ambiental sob os olhares de cada ator do espaço social (DIAS; MARQUES; DIAS, 2016)

A iniciação à Educação Ambiental requer vários passos e métodos que vão além das aulas nas escolas, a construção de uma consciência ambiental é dada ao longo de uma vida inteira a partir de ensinamentos, exemplos de familiares, pequenas atitudes, e o mais importante, o sentimento de preocupação com o meio que nos rodeia. Porém, é na escola que os alunos possuem contato mais abrangente com as questões ambientais, e a escolha

revista brasileira educação ambiental 
das metodologias do professor é muito importante no desenvolvimento do aluno como indivíduo perante a sociedade. Deste modo, os professores abordam vários temas e utilizam recursos didáticos que são extremamente úteis para trabalhar a Educação Ambiental de forma interdisciplinar, favorecendo a compreensão de que todos os fatores que compõem o meio ambiente são conectados. Além disso, segundo Santos, Bonini e Sartonello (2017), as diferentes paisagens escolares, urbanas ou rurais, podem explorar os próprios elementos para as aulas de Educação Ambiental, levando em consideração os problemas ambientais voltados a essas realidades. Portanto, é essencial que cada vez mais a Educação Ambiental entre em favor da conservação da natureza, fazendo com que os seres humanos compreendam o quão importante é o meio onde vivem, tornando-se cada vez mais conscientes.

O presente estudo tem por finalidade identificar a influência do ambiente escolar na escolha das metodologias de Educação Ambiental de professores dos anos iniciais do ensino fundamental de uma escola do campo. Assim, o objetivo é analisar o uso do ambiente escolar (área externa) pelo professor para a prática didática, caracterizar as práticas pedagógicas em turmas multisseriadas no trabalho com questões ambientais e compreender as relações entre o meio rural e a formação dos alunos. Para atingir os objetivos propostos foi realizado um questionário com os professores dos anos iniciais do ensino fundamental da Escola Estadual de Ensino Fundamental 15 de Março da cidade de Júlio de Castilhos, RS. O questionário é uma técnica de investigação que se constitui em perguntas por escrito às pessoas que se deseja pesquisar, além disso, possui uma série de vantagens quando comparado a entrevista, como permitir que as pessoas respondam no momento que julgar mais conveniente, e não expõe o pesquisador e 0 entrevistado à influências de opiniões (PHILIPPI JR; PELICIONI, 2005).

\section{Revisão bibliográfica}

\section{Práticas pedagógicas}

A prática educativa necessita estar alicerçada em uma pedagogia transformada em ação, pois caso contrário há um acúmulo de teorias, pensamentos, e estratégias de ações que não nascem, como se fosse possível ficar sempre no processo de gestação (MACHADO; CAMPOS; PALUDO, 2008).

Assim, segundo Gonçalves e Diehl (2012), é preciso ter uma base das ações educativas que visam a formação de cidadãos éticos e participativos, que consolidem uma relação respeitosa e harmoniosa consigo mesmo, com os outros e com o ambiente. A contribuição da escola/educação auxilia para que ocorram atitudes de cuidado com o ambiente, pois as causas ambientais necessitam que todas as áreas do conhecimento dialoguem e busquem alternativas para o convívio de todos (PAIXÃO; MEURER, 2016). 
Silva (2016) ressalta a importância das atividades práticas relacionadas à Educação Ambiental no contexto escolar, de modo, a incentivar os educandos a participarem constantemente das atividades escolares. Pois a criação de atividades práticas possui ações mais efetivas bem como apresentam concepções reais, inseridas no cotidiano dos alunos, promovendo a sensibilização mais crítica ao ambiente que estão inseridas (BARRETO; CUNHA, 2016).

A interdisciplinaridade vem sendo uma ferramenta para os docentes, principalmente na formação social e ecológica de discentes, pois segundo Silva e Santana (2020), pode atender às novas exigências sociais no contexto escolar, de modo a favorecer a formação dos alunos para atuarem de forma crítica e reflexiva perante a sociedade. Assim, é de suma importância no âmbito escolar, envolver disciplinas com mesmo propósito, pois é uma forma de transmitir aos alunos uma nova dinâmica de metodologia aplicada, permitindo um elo entre as disciplinas e as temáticas abordadas.

Desse modo, é essencial que as práticas pedagógicas voltadas para o meio ambiente possam contribuir com a formação de educandos críticos, participativos e preocupados com o ambiente. Além de incentivar os alunos a terem diferentes perspectivas e a partir disto, construírem um pensamento conectivo entre o indivíduo, o coletivo e o ambiente (GONÇALVES; DIEHL, 2012).

\section{Educação do campo}

O Ministério da Educação, ao dispor sobre as políticas de educação do campo e o Programa Nacional de Educação na Reforma Agrária - PRONERA, através do Decreto № 7.352, de 4 de novembro de 2010, possui a seguinte definição sobre Populações do Campo e escolas do campo (BRASIL, 2010):

I - populações do campo: os agricultores familiares, os extrativistas, os pescadores artesanais, os ribeirinhos, os assentados e acampados da reforma agrária, os trabalhadores assalariados rurais, os quilombolas, os caiçaras, os povos da floresta, os caboclos e outros que produzam suas condições materiais de existência a partir do trabalho no meio rural; e.

II - escola do campo: aquela situada em área rural, conforme definida pela Fundação Instituto Brasileiro de Geografia e Estatística - IBGE, ou aquela situada em área urbana, desde que atenda predominantemente a populações do campo (MEC, 2012).

Segundo Santos e Santos (2017, p. 5) "A escola do meio rural possui papel fundamental para a comunidade, pois ela consegue manter as crianças em seu local de convívio, evitando a necessidade de se deslocarem para a cidade". A maioria da população do campo vive direta ou indiretamente da 
produção familiar, logo, dependem de recursos naturais e de outros seres vivos para sobrevivência como produtores rurais. Assim, educação é voltada para esta realidade, e segundo Kolling, Cerioli e Caldart (2002, p. 27) "A perspectiva da educação do campo é exatamente a de educar este povo, estas pessoas que trabalham no campo, para que se articulem, se organizem e assumam a condição de sujeitos da direção de seu destino", consolidando as vivências adquiridas no dia-a-dia com o trabalho no campo.

\section{Educação Ambiental}

Segundo Carvalho (2011), a Educação Ambiental surge da preocupação da sociedade com o futuro e com a qualidade da existência das presentes e futuras gerações. Ainda, visa construir novas maneiras da sociedade se relacionar com o meio ambiente. É preciso não só saber o que é certo ou errado em relação ao ambiente, mas também agir, sensibilizar a sociedade de forma que envolva o sentimento de cuidar, preservar, e o compreender racionalmente o meio onde vivem (GUIMARÃES, 2011)

De acordo com Loureiro (2011), a Educação Ambiental produz e reproduz as relações da sociedade as quais, para serem transformadas, dependem de uma educação crítica e de várias outras modificações políticas, sociais, econômicas e culturais.

O processo de transformação da sociedade no âmbito da Educação Ambiental inicia-se com indivíduos transformados ecologicamente, e cada um fazendo uma parte, porém, o objetivo do processo educativo deve ser voltado ao coletivo, gerando uma sociedade comprometida com o meio (GUIMARÃES, 2011). Desse modo, a Educação Ambiental é uma ferramenta importantíssima, gerando assim, novos comportamentos ecológicos entre os cidadãos (CANDAMIO; NOVO; GARCIA, 2018).

Conforme Carvalho (2011), a visão socioambiental orienta-se por uma racionalidade complexa e interdisciplinar e pensa o meio ambiente não como sinônimo de natureza intocada, mas como um campo de interações entre a cultura, a sociedade e a base física e biológica dos processos vitais, no qual todos os termos dessa relação se modificam dinamicamente e mutuamente. Deste modo, a Educação Ambiental vem sendo desenvolvida cada vez mais nas escolas brasileiras, dando grande importância para iniciativas da comunidade escolar sobre Educação Ambiental. A interconexão do que está fora e dentro da escola, na realidade local e global faz com que o ambiente seja uma realidade complexa (GUIMARÃES, 2011)

Segundo Leme (2006), os professores devem diagnosticar e fazer ligações de como as questões socioambientais possuem implicações sociais, econômicas, ecológicas. Além disso, 
Os professores devem ser capazes não somente de identificar e interpretar os múltiplos conflitos e dimensões da sociedade, mas de fazer com que os estudantes também desenvolvam essa habilidade; é importante que todos - professores, alunos e comunidade - queiram transformar a realidade social (LEME, 2006, p. 110).

Durante o processo de construção do conhecimento, é essencial que os alunos se tornem sujeitos capazes de compreender o mundo e agir de forma crítica, em que:

Os princípios e valores ambientais promovidos por uma pedagogia do ambiente devem enriquecer-se com uma pedagogia da complexidade, que induza nos educandos uma visão da multicausalidade e das inter-relações dos diferentes processos que integram seu modo de vida nas diferentes etapas de desenvolvimento psicogenético; que gere um pensamento crítico e criativo baseado em novas capacidades cognitivas. (LEFF, 2009, p. 243)

Segundo Leme (2006), há uma enorme diferença entre as histórias de vida e posturas dos professores perante o tema, alguns mais comprometidos e outros menos, porém, é importante levar em conta que muitos deles não tiveram referenciais teóricos da Educação Ambiental, assim como podem não conhecer os objetivos e princípios:

O princípio de sustentabilidade surge no contexto da globalização como a marca de um limite e o sinal que reorienta o processo civilizatório da humanidade. A crise ambiental veio questionar a racionalidade e os paradigmas teóricos que impulsionaram e legitimaram o crescimento econômico, negando a natureza. A sustentabilidade ecológica aparece assim como um critério normativo para a reconstrução da ordem econômica, como uma condição para a sobrevivência humana e um suporte para chegar a um desenvolvimento duradouro, questionando as próprias bases de produção (LEFF, 2009, p. 15).

Assim, a Educação Ambiental é um meio de modificação da atual situação em meio aos problemas ambientais enfrentados, modificando as formas de pensar dos sujeitos, a se tornarem críticos, conscientes e sustentáveis. 


\section{Problemas ambientais}

As questões ambientais vêm sendo discutidas cada vez mais ao logo dos anos à medida que cresce a modificação do ambiente. Estes problemas ambientais têm causados uma série de devastações na natureza, afetando além dos recursos naturais, todos os seres vivos que nela habitam. De acordo com Miller e Spoolman (2012), os problemas ambientais possuem como principais causas o crescimento populacional, o uso insustentável de recursos, e a não inclusão dos custos ambientais de bens e serviços nos preços de mercado.

Temos que desvelar e agir sobre as relações que originaram os problemas ambientais (suas causas epistemológicas, éticopolíticas, materiais, etc.) e não apenas nos restringirmos a, no máximo, informar as suas consequências (GUIMARÃES, 2011, p. 84).

É, portanto, indispensável perceber as causas dos problemas ambientais para compreender as várias dimensões que estão contidas neste contexto, assim,

Promover a compreensão dos problemas socioambientais em suas múltiplas dimensões: geográfica, histórica, biológica e social, considerando o meio ambiente como o conjunto das inter-relações entre o mundo natural e o mundo social, mediado por saberes locais e tradicionais, além de saberes científicos (CARVALHO, 2011, p. 158).

É essencial que seja compreendido que essas degradações do ambiente são causadas pelas atividades humanas, em grande maioria. Além disso, as consequências geradas são sentidas por todos os organismos vivos a curto e longo prazo. Porém há muita divergência de opiniões sobre estas atividades e a degradação do ambiente, pois a maioria das pessoas não consegue fazer a ligação das atitudes com as consequências geradas ao passar dos anos. Estes pensamentos dependem de vários fatores que foram sendo construindo ao longo da vida de uma pessoa, a partir de vivências ou ensinamentos, em que as ações são baseadas na visão de mundo deste indivíduo (MILLER e SPOOLMAN, 2012).

Miller e Spoolman (2012) destacam a importância da ética ambiental, e crenças sobre o que é certo e errado em relação ao modo como tratamos o meio ambiente. 


\section{Metodologia}

Foi realizado um estudo no ano de $2018 \mathrm{com}$ os professores dos anos iniciais do ensino fundamental da Escola Estadual de Ensino Fundamental 15 de Março, a partir da proposta de um estudo de caso.

A escola é localizada no assentamento Nova Ramada no município de Júlio de Castilhos, RS, à $20 \mathrm{~km}$ do centro da cidade, sendo denominada escola do campo (Figura 1). Segundo o INEP (2017), no Rio Grande do Sul aproximadamente $7,8 \%$ das matrículas realizadas para os anos iniciais do ensino fundamental foram em escolas estaduais rurais, ou seja, em escolas do campo.

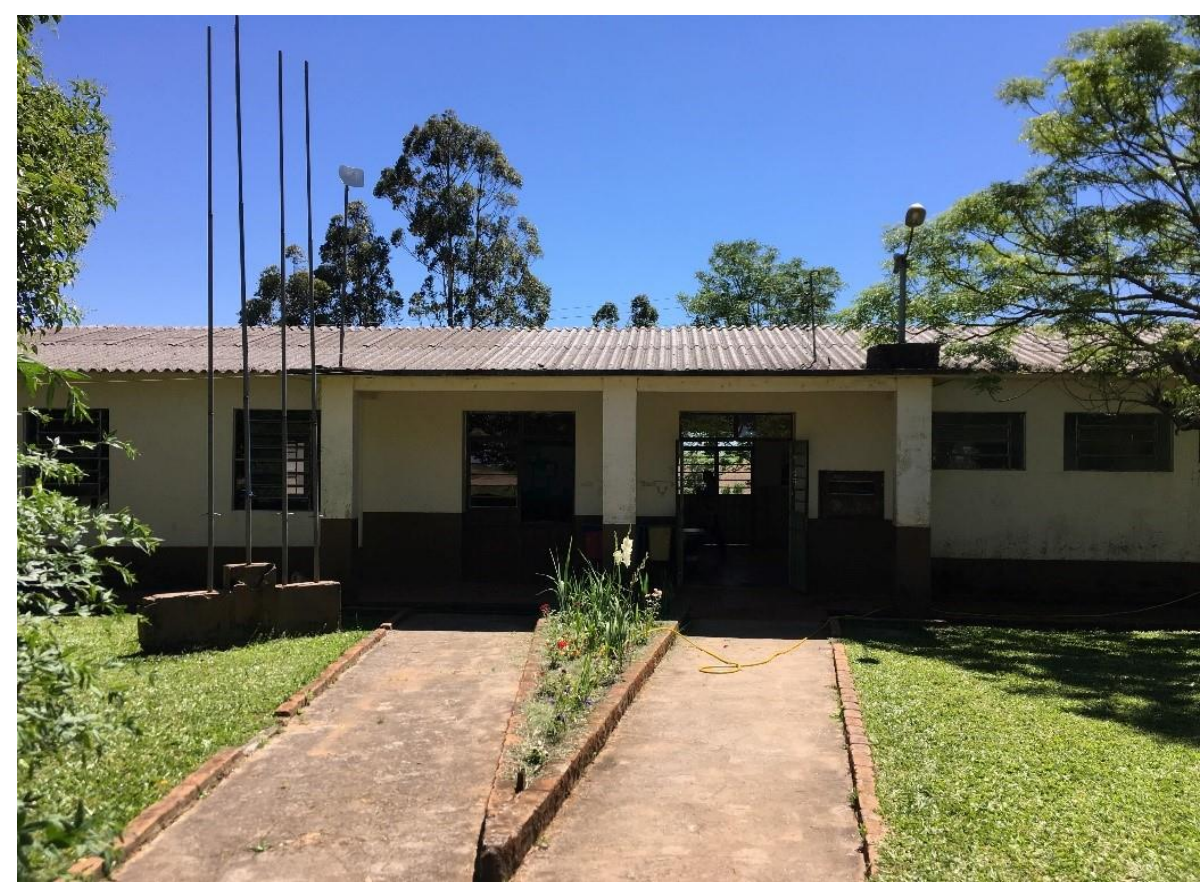

Figura 1: Entrada da Escola Estadual de Ensino Fundamental 15 de Março.

Fonte: Autora (2018).

A Escola iniciou as atividades no ano de 1989 e possui características e finalidades ligadas ao MST (Movimento dos Trabalhadores Rurais Sem Terra), pois a história da escola está diretamente ligada à história da comunidade da Ramada, onde está localizada. A desapropriação da área considerada improdutiva ocorreu dia 15 de março de 1989, sendo liberada para o assentamento de cem famílias, e à medida que as famílias foram se organizando no assentamento, havia também a preocupação com a educação dos filhos. Sendo assim, a escola sempre organizou as atividades, currículo e planejamentos de acordo com as necessidades e objetivos da comunidade. Já no Projeto Político Pedagógico (PPP) da escola é reforçada a ideia de que há uma grande ligação entre a educação e a realidade da comunidade. Sendo então a concepção de educação: 
É fundamental na concepção de que a educação é um processo contínuo que valorize a realidade dos sujeitos $\mathrm{e}$ preserve suas raízes, proporcionando condições para que possam perceber e construir sua história. Auxiliando - o a compreender o mundo onde está inserido, refletir sobre ele, faça opção de valores e agir de modo comprometido. Que trabalhe e mantenha a inter-relações com o meio desenvolvendo o espírito de cooperação, construindo os valores necessários ao novo homem e a nova mulher na construção da nova sociedade (PPP, 2006, p. 4).

A área pertencente à Escola é de $10000 \mathrm{~m}^{2}$, sendo o prédio com área construída de $485 \mathrm{~m}^{2}$. Na parte externa, possui árvores nativas, árvores frutíferas e canteiros de flores e chás (figuras 2 e 3). Em época que a escola funcionava em dois turnos, existia a horta e a estufa. No contra turno havia tempo disponível, quando os alunos auxiliavam na produção de hortaliças e podendo consumi-las, porém estão desativadas.

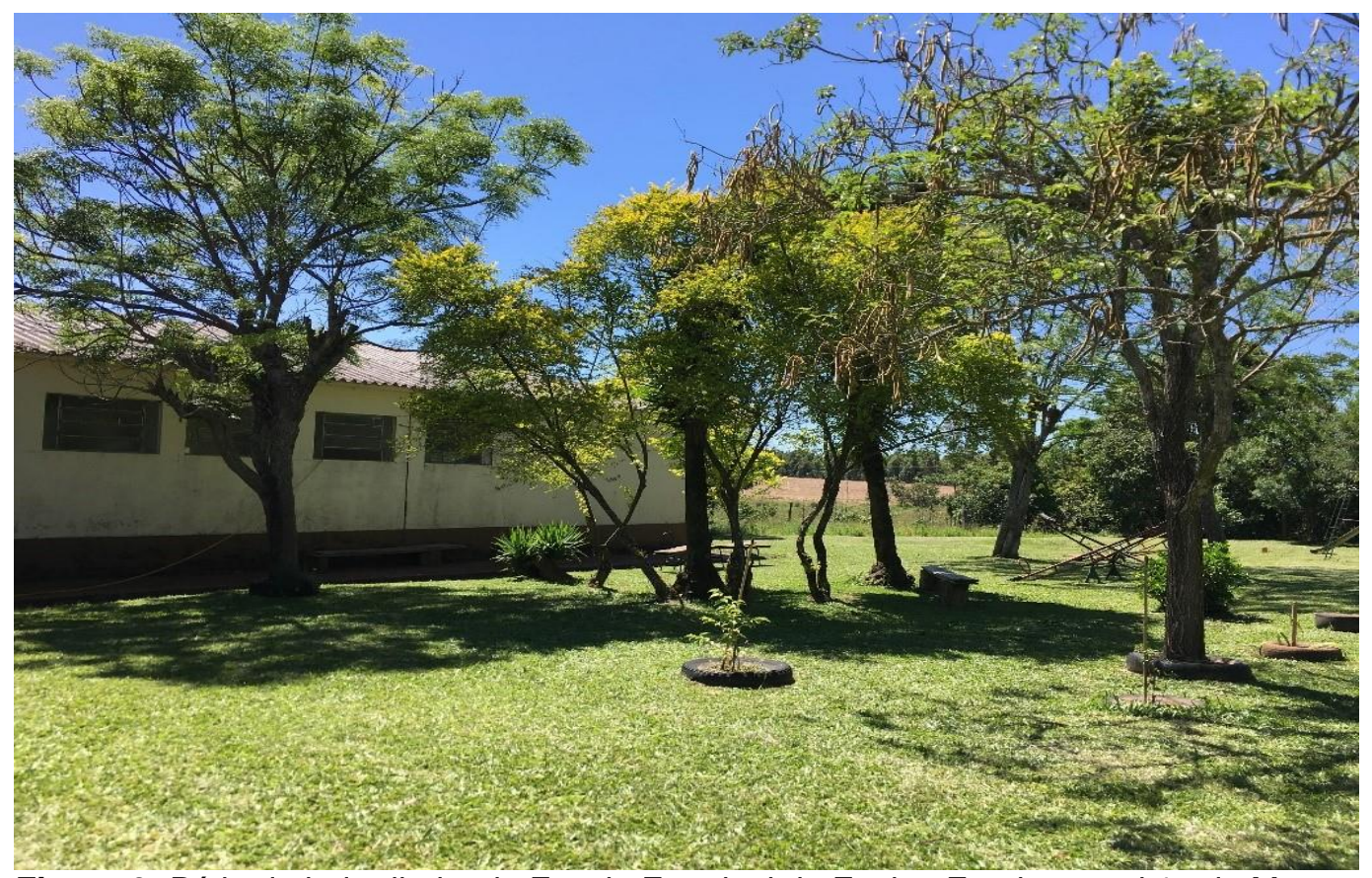

Figura 2: Pátio do lado direito da Escola Estadual de Ensino Fundamental 15 de Março.

Fonte: Autora (2018). 


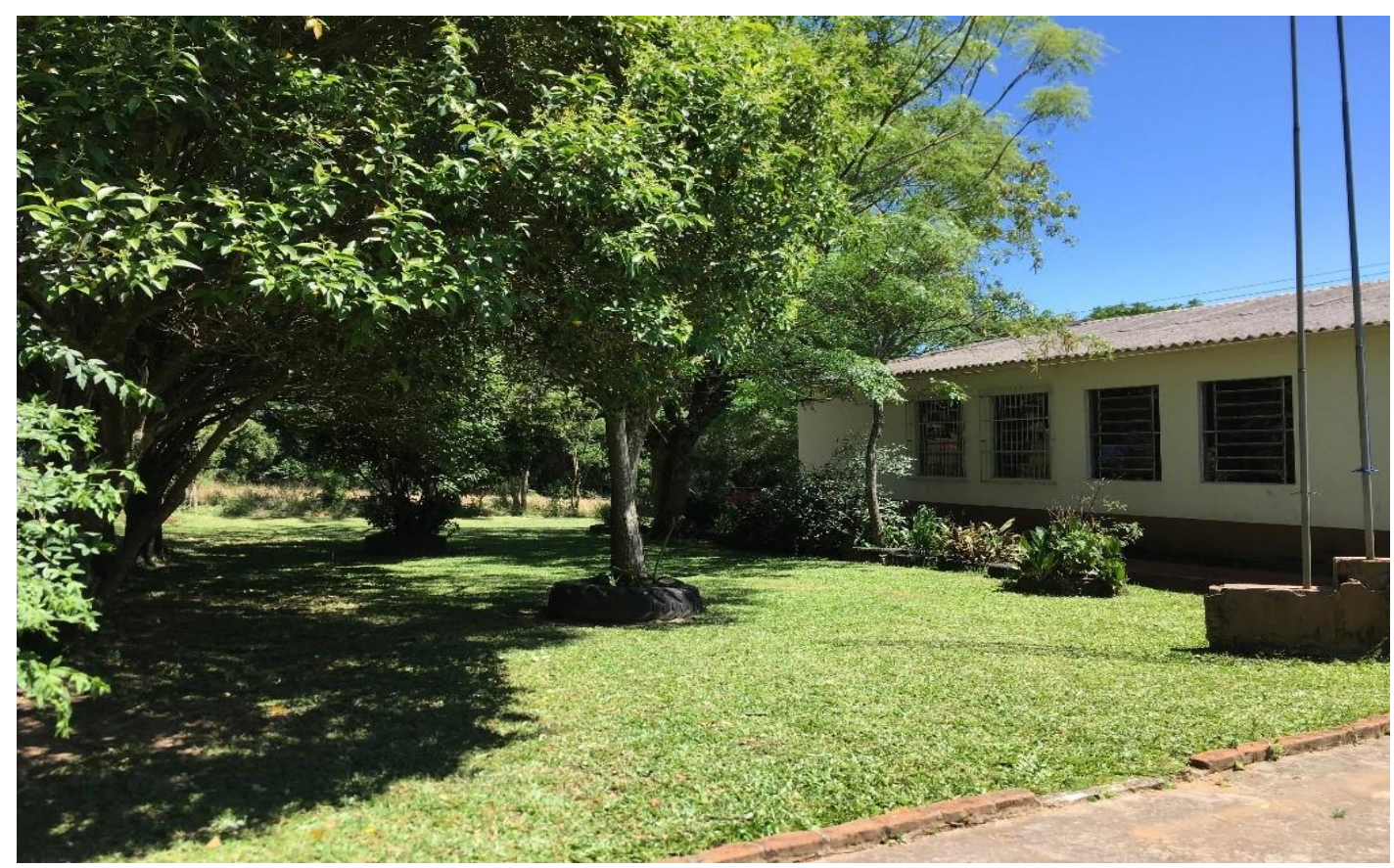

Figura 3 : Pátio do lado esquerdo da Escola Estadual de Ensino Fundamental 15 de Março.

Fonte: Autora (2018).

No ano do estudo, a escola funcionava somente no turno da manhã, contando 47 alunos distribuídos entre a pré-escola e o 9ำ ano, todos residindo na comunidade, seis professores, sendo a maioria da zona urbana da cidade e se deslocando até a escola, uma merendeira, a coordenadora pedagógica e o diretor. As turmas eram multisseriadas devido ao pequeno número de alunos, e por este motivo o professor trabalhava com diferentes idades e níveis de aprendizado na mesma turma.

Participaram da pesquisa duas professoras do sexo feminino com $35 \mathrm{e}$ 53 anos de idade, com formação em Pedagogia, uma atendia os alunos do $1^{\circ}$ ao $3^{\circ}$ ano, e a outra trabalhava com o $4^{\circ}$ e $5^{\circ}$ ano. Para coletar as informações da pesquisa foi realizado um questionário com 12 perguntas, as quais estão organizadas de acordo com os objetivos propostos neste estudo, tendo três perguntas referentes a cada objetivo específico. Os professores tiveram sete dias para responder e entregar. Para a análise das questões, foram adotados critérios específicos para cada objetivo proposto. Para o primeiro objetivo, que era apontar o uso do meio externo da escola pelo professor para a prática pedagógica, foi estabelecido parâmetros como, frequente, infrequente ou raras vezes. Para o segundo objetivo que foi verificar a prática pedagógica em turmas multisseriadas ao trabalhar as questões ambientais, foram analisadas 0 grau de diversificação das aulas para que o aluno compreenda a importância do meio ambiente, bem como a interdisciplinaridade aplicada pelo professor em suas aulas. Já para o terceiro objetivo que era verificar a influência do meio rural na formação dos alunos, foi analisada a percepção dos professores em atentarem para o grau de ligação que os alunos fazem do dia a dia em casa, no campo, com as aulas de Educação Ambiental.

revista brasileira educação ambiental 


\section{Resultados e discussão}

Os dados apresentados são resultantes da aplicação do questionário, onde foram observadas as perguntas e discutidas as respostas obtidas pelos professores.

Três questões tinham por objetivo apontar o uso do ambiente escolar pelo professor para a prática didática. As professoras responderam que utilizavam ferramentas como livros, revistas, pesquisas na internet, que conseguiam realizar interdisciplinaridade e que as aulas práticas no pátio da escola dependiam do conteúdo, mas que poucas ou raras vezes eram um recurso usado. De acordo com Santos e Santos (2016), o currículo rigidamente disciplinar e a falta de suporte teórico e metodológico são fatores que limitam a Educação Ambiental nas escolas, além disso, o descompasso entre teorias, metodologias, pedagogias e aplicabilidade são desafios ao trabalhar a interdisciplinaridade em Educação Ambiental (MIRANDA; MIRANDA, 2010).

Através das questões aplicadas foi possível notar que a área externa da escola era pouco utilizada durante as aulas de Educação Ambiental, sendo que os professores ainda preferiam a utilização de revistas e internet. Assim, raras às vezes a metodologia do professor envolvia aulas práticas no pátio da escola. Segundo Scortegagna e Negrão (2005, p. 37) "é no campo que o aluno poderá perceber e aprender os vários aspectos que envolvem o seu estudo, tanto naturais quanto sociais". Além disso, torna as aulas mais dinâmicas e mais atrativas (MARTINS; SANCHEZ, 2020).

As próximas questões analisavam as práticas pedagógicas em turmas multisseriadas ao trabalhar as questões ambientais. As professoras salientaram que a prática em turmas multisseriadas possuía pontos positivos, já que os alunos trocavam informações entre eles, havia interdisciplinaridade e os conteúdos eram iguais, porém com níveis de aprofundamento diferentes. Assim, as respostas afirmaram que as professoras percebiam vantagens ao trabalhar com turmas multisseriadas, pois havia troca de informações entre os alunos, o que enriquece as aulas.

As escolas multisseriadas podem ser compreendidas como uma possibilidade de desenvolver um processo educativo diferente, em que alunos de diversas faixas etárias e experiências podem participar e criar formas coletivas de apropriação do conhecimento (SANTOS; SANTOS, 2017, p.7).

Porém os professores não citaram muitas desvantagens, faltando este aspecto nas respostas. Apesar disso, acredita-se que a educação do campo assim como as classes multisseriadas possuem propriedades específicas especiais, pois além do professor ter a dificuldade de trabalhar com anos diferentes no mesmo espaço, ainda precisa adaptar o conteúdo à realidade de vida dos alunos. Sabendo que, um dos princípios da Escola do Campo é 
justamente a necessidade de articular a escola com a vida, além da importância das experiências cotidianas (JANATA e ANHAIA, 2015).

As últimas questões se referiram a verificar a influência do meio rural na formação dos alunos. As professoras observaram que os alunos faziam a ligação da vida diária, com os conhecimentos adquiridos na escola. Notou-se com tais respostas que a vida cotidiana interfere na aprendizagem do aluno quando este relaciona vivências em casa com os ensinamentos da sala de aula, favorecendo a concepção de que escola e a realidade do sujeito andam juntos. Além disso, quando a professora levava para a sala de aula temas que se ligam ao dia a dia dos alunos, chamava a atenção destes e faziam a ligação sala de aula com a vida no campo. Sendo assim, acredita-se que o meio rural interferia na formação no aluno, ampliando a visão do mundo:

A noção de espaço é construída socialmente e a criança vai ampliando e complexificando 0 seu espaço vivido concretamente. A capacidade de percepção e a possibilidade de sua representação é um desafio que motiva a criança desencadear a procura, a aprender a ser curiosa, para entender o que acontece ao seu redor, e não ser simplesmente espectadora da vida (CALLAI, 2005, p. 229).

Conforme as respostas, verificou-se que os professores tendiam a utilizar recursos limitados como livros e internet, e não usufruir da biodiversidade existente no pátio da escola para práticas de Educação Ambiental. Apesar disso, salientaram que era possível realizar a interdisciplinaridade em aulas de Educação Ambiental. Além disso, como as turmas eram multisseriadas, os conteúdos eram trabalhados em níveis diferentes, buscando relacionar com a vida no campo, o que resultava na ligação entre sala de aula e dia a dia no meio rural. Portanto, a maior parte das aulas de Educação Ambiental tornava-se influenciada pelo ambiente escolar.

\section{Conclusões}

Conclui-se que a escola do campo estudada não utiliza frequentemente as áreas externas para aulas práticas como uma ferramenta a favor da Educação Ambiental. Porém, as turmas multisseriadas permitem realizar a interdisciplinaridade e a troca de saberes entre os alunos, além de relacionar experiencias do dia a dia no meio rural dentro da sala de aula.

Este estudo possui bases para que possam ser realizadas novas pesquisas que venham a contribuir com as aulas de Educação Ambiental nas escolas, de modo a aproximar os conteúdos didáticos a realidade rural dos alunos. Além disso, possui a função de alertar para a influência das metodologias utilizadas pelos professores na construção da consciência ambiental dos discentes. 


\section{Referências}

BARRETO, L. M.; CUNHA, J. S. Concepções de meio ambiente e Educação Ambiental por alunos do ensino fundamental em Cruz das Almas (BA): um estudo de caso. Revista Brasileira de Educação Ambiental, São Paulo, v. 11, n. 1, p. 315-326, 2016.

BRASIL. Decreto no 7352, de 4 de novembro de 2010. Disponível em: $<$ http://portal.mec.gov.br/docman/marco-2012-pdf/10199-8-decreto-7352-de4de-novembro-de-2010/file>. Acesso em: 12 abr. 2018.

CALLAI, H.C. Aprendendo a ler o mundo: A geografia nos anos iniciais do ensino fundamental. Cadernos Cedes. Campinas, v.25 n. 66, p.227-247, 2005.

CANDAMIO, L.V.; NOVO, I.C.; GARCIA, M.T.G. The importance of environmental education in the determinants of green behavior: A meta-analysis approach. Elsevier - Journal of Cleaner Production, Amsterdã, v. 170, n. 1, p. 1565-1578, 2018.

CARVALHO, I. C. M. Educação Ambiental: a formação do sujeito ecológico. São Paulo: Cortez, 2011.

CRUSOÉ, N. M. C. Prática Pedagógica interdisciplinar na Escola Fundamental: sentidos atribuídos pelas professoras. Curitiba: CRV. 2014.

DIAS, L. S.; MARQUES, M. D.; DIAS, L. S. Utilização do Acervo Educacional de Ciências Naturais da Unoeste para a Educação Ambiental. In: DIAS, L. S.; MARQUES, M. D.; DIAS, L. S. Educação Ambiental: conceitos, metodologia e práticas. Tupã: ANAP, 2016.

ESCOLA ESTADUAL DE ENSINO FUNDAMENTAL 15 DE MARÇO. Proposta Política Pedagógica, 2006.

GONÇALVES, C. S. DIEHL, L. S. et al. Educação Ambiental: da teoria à prática. Porto Alegre: Mediação, 2012.

GUIMARÃES, M. A formação de educadores ambientais. Campinas, SP: Papirus, 2011.

GUIMARÃES, M. Caminhos da Educação Ambiental: da forma a ação. Campinas, SP: Papirus, 2011.

INEP. Instituto Nacional de Estudos e Pesquisas Educacionais Anísio Teixeira. 2017.

JANATA, N. E., ANHAIA, E. M. Escolas/Classes Multisseriadas do Campo: reflexões para a formação docente. Educação e Realidade. Porto Alegre, v.40. n.3, p. 685-704, Jul/Set, 2015.

KOLLING, E. J. CERIOLI, P. R. CALDART, R. S. Educação do campo: identidade e políticas públicas. Brasília: articulação nacional por uma Educação do Campo, 2002. 
LEFF, E. Saber ambiental: sustentabilidade, racionalidade, complexidade, poder. Petrópolis, RJ: Vozes. 2009.

LEME, T, N. Conhecimentos práticos dos professores e sua formação continuada: um caminho para a Educação Ambiental na escola. Caminhos da Educação Ambiental: da forma à ação. Campinas, SP: Papirus, 2006.

LOUREIRO, C. F.B. LAYRARGUES, P. P. CASTRO, R. S. Educação Ambiental: repensando o espaço da cidadania. São Paulo: Cortez, 2011.

MACHADO, C. L. B. CAMPOS, C. S. PALUDO, C. Teoria e prática da educação do campo: análises de experiências. Brasília: MDA, 2008.

MARTINS, P. SANCHEZ, C. Educação Ambiental escolar: Caminhos e cruzamentos rumo a Educação Ambiental crítica. Educazione aperta, n.7, 2020.

MILLER, G. T. SPOOLMAN, S. E. Ecologia e sustentabilidade. São Paulo: Cengage Learning, 2012.

MIRANDA, F. H. F. MIRANDA, J. A. Abordagem interdisciplinar em Educação Ambiental. Revista Práxis, n. 10, 2010

PAIXÃO, E. L. MEURER, A. C. Educação Ambiental: Escolas sustentáveis e com vida. Santa Maria: Editora e gráfica Caxias, 2016.

PHILIPPI JR, A. PELICIONE, M. C. F. Educação Ambiental e sustentabilidade. Barueri, SP: Manole, 2005.

SANTOS, R. S. SANTOS, M. Educação do campo: classes multisseriadas e seus desafios pedagógicos. Educação, base nacional comum curricular e formação do professor. Aracaju, v.10, p. 1-13, maio, 2017.

SANTOS, A. G. SANTOS, C.A.P. A inserção da Educação Ambiental no currículo escolar. Revista Monografias Ambientais. v.15, n.1, 2016.

SANTOS, W. A.; BONINI, L. M. M.; SARTORELLO, R. Contribuições da paisagem rural e urbana para práticas pedagógicas de Educação Ambiental. Fórum ambiental da Alta Paulista. V. 13, n.04, 2017.

SILVA, S. G. Educação Ambiental Escolar: Estudando Teorias e Visualizando Iniciativas Realizadas no Colégio Módulo em Juazeiro do Norte-CE. Geosaberes, v. 6, n. esp. 3, p. 16-26, 2016.

SILVA, M. F. G. SANTANA, I. M. Interdisciplinaridade nas práticas docentes de professoras da educação básica. Imagens da Educação, v. 10, n.2, p. 65-79, 2020.

SORTEGAGNA, A.; NEGRÃO, O. Trabalhos de campo na disciplina de Geologia Introdutória: a saída autônoma e seu papel didático. Terra e didática. Campinas, v.1, p. 36-43, 2005.

SECADI. Secretaria de Educação Continuada, Alfabetização, Diversidade e Inclusão. Educação do Campo: marcos normativos. Brasília, 2012. 